\title{
DEVELOPING STUDENT CREATIVITY IN AN ENGINEERING CONTEXT
}

\author{
Tallman, K.M. \\ Engineering Communication Program, University of Toronto, Ontario Canada \\ k.tallman@utoronto.ca
}

INTRODUCTION
This presentation discusses and analyzes an approach to developing student creativity in an elective course at the Faculty of Applied Science and Engineering, University of Toronto. In APS325: Engineering and Science in the Arts, students create original works of art that are connected to engineering or science and present these works to their classmates at the end of term. Through this central activity and other smaller assignments, the course offers students the opportunity to build their creativity in a context that includes engineering but also extends beyond standard engineering practice. This study will analyze examples of the students' work; as well, it will identify the students' metacognitive discoveries during and after the course and how these discoveries helped the students develop their creative abilities, both in their engineering studies and in activities outside their discipline. Finally, this study will identify creativity theories and techniques that might be incorporated into this course in the future.

\section{THEORETICAL BACKGROUND}

Techniques for enhancing creativity are now ubiquitous. Websites such as mindtools.com show the familiar (brainstorming, TRIZ, SCAMPER, Synectics) and the less familiar (Kano Model Analysis, Provocation, Starbursting), reminding us that creativity has become a major enterprise, essential, we are told, for success in many fields. ${ }^{1}$ In the study of creativity in the sciences, and how this creativity may have relevance in the arts, scholarship from the field of psychology offers particularly useful hypotheses and models.

From psychology, Dean Keith Simonton presents four possible models for creativity in science - chance, logic, genius, and zeitgeist arguing that all four may play a role, with chance being the first among equals. ${ }^{2}$ To support the prominence he gives to chance in the creative process, Simonton, like Sarnoff Mednick ${ }^{3}$ before him, points to two seminal statements, one by the mathematician Poincare and one by the theoretical physicist Einstein. In 1921, Poincaré related an experience in which "ideas arose in crowds; I felt them collide until pairs interlocked so to speak, making a stable combination. By next morning I had established the existence of a class of Fuchsian functions." From this experience, Poincaré concluded that "to create consists of making new combinations of associative elements which are useful. . . Among chosen combinations the most fertile will often be those formed of elements drawn from domains which are far apart." In a 1945 testimonial, Einstein, responding to a psychological survey of mathematicians to determine how they think, stated, "[T]aken from a psychological viewpoint, this combinatory play seems to be the essential feature in productive thought" ${ }^{\text {"4 }}$ Like Poincaré, Einstein places high value in the associative basis of the creative process, suggesting, like Poincaré, that creativity is often more stochastic than it is deterministic, operating primarily through conjecture, chance, and random variables rather than through deliberate and logical means.

\section{COURSE BACKGROUND}

In its first iteration, in Fall 2012, APS325 attracted a small group of 12 students. The main goal of the course was to give engineering students the opportunity to extend their creativity beyond standard engineering practice. As mentioned before, the central end-of-term assignment required each student to create an original work of art and to present the work to the class, explaining its connection to engineering or science. As well, each student led a seminar presentation on a selected artist or artistic movement, and, as a group, we visited an art gallery and a theatre production, each student submitting a written analysis of one work's connection to engineering or science.

In Fall 2013, in its second iteration, with a class of 17 students, the most notable change was the introduction of readings and discussion that required students to reflect on their own creative processes. This activity became particularly fruitful toward the end of term, when students were completing their main projects (their works of art) and were able to look back and assess their journeys and then use these insights to further develop their art works. Various new class readings on creativity and the subsequent class discussions of these texts gravitated toward the theory discussed above. In these discussions, students showed particular interest in the value of combinatory play in the creative process. As well, we used art theory, from the classical (Plato and Aristotle) to the modern
(Clement Greenberg and Susan Sontag), to help develop a vocabulary to assess the art we were studying and the art the students were creating. METHODS

This study analyzes creativity using two sets of data. First, I have selected samples of the students' art works. Here, I am interested not only in the works themselves but also in the creative processes the students developed to complete the works. Secondly, I am presenting and analyzing statements made by the students during a focus group that took place after the course concluded. I organized the focus group to gain a clearer understanding of the students' experiences in the course and their individual insights into their creative processes. One of the students in the course facilitated the focus group, ensuring that all participants in the focus group remained anonymous. Lastly, this study will present activities that may become part of the course requirements in the course's next iteration. These activities, based on concepts inspired by "combinatory play," may include flat-slope associative thinking, a state in which a person is able to offer many associative responses to a situation or problem, and Janusian thinking, a state in which a person practices conceiving associative opposites as part of the creative process.

\section{RESULTS}

While the results are not yet complete, certain trends are apparent. Students in the course tend to do their creative work stochastically. Rather than following a logical, deterministic path, they more often follow an unpredictable path, with chance occurrences and unexpected combinations characterizing the development path.

\section{DISCUSSION}

Students, while in the course and afterwards, clearly stated that their creativity in the class followed a stochastic process. This reinforces the hypotheses of leading psychologists and is also consistent with the introspective statements of practitioners such as Poincaré and Einstein.

\section{REFERENCES}

1. Mind Tools: Essential Skills for an Excellent Career, 1996-2014. http://www.mindtools.com/pages/main/newMN_CT.htm Accessed May 15, 2014.

2. Simonton, D.K. Creativity in Science: Chance, Logic, Genius, and Zeitgeist. Cambridge, UK: Cambridge University Press, 2004.

3. Mednick, S.A. "The Associative Basis of the Creative Process," Psychological Review, 69, 1962, 220-232.

4. Poincaré, H. The Foundations of Science: Science and Hypothesis, The Value of Science, Science and Method. G.B. Halstead, Trans. New York: Science Press, 1921.

5. Einstein, A. Ideas and Opinions. S. Bargmann, Trans. New York: Modern Library, 1954. 